\title{
ene
}

\section{LAS ENFERMERAS CUIDAN}

\author{
Alfonso M. García Hernández \\ Universidad de La Laguna
}

“¿Qué disciplina dejaremos a nuestras enfermeras?

¿Qué cuidados daremos a nuestros semejantes?”

En estos tiempos convulsos que nos ha tocado vivir es posible que tengamos que regresar en más de una ocasión a la reflexión de la esencia de nuestra razón de ser como disciplina "las enfermeras cuidan". Quizá realizando la acción tan humana de caminar como rodeo para encontrarnos a nosotros mismos.

Aprender a vivir es posible y aprender a ayudar a vivir y a cuidarse una necesidad. Vivimos un tiempo en que cada vez es más necesario enseñar a cuidar, enseñar la profesión del cuidado y aprender y enseñar a cuidar y cuidar a los demás. A vivir se aprende con las experiencias propias y con la ayuda de la poesía, el amor de quienes nos rodean, sabiendo leer, escribir y contar, además de recibir buenos cuidados a lo largo de nuestra vida, pero necesitamos algunos ingredientes más.

La Escuela y la Universidad nos acercan conocimientos, pero no la propia naturaleza del mismo, sino una reconstrucción e interpretación de los mismos. Estamos condenados a la interpretación y necesitamos métodos para que nuestras percepciones, ideas y distintas visiones del mundo sean fiables y nos acompañen en nuestras decisiones. Crear nuestras certidumbres no es tarea fácil, pues están jalonadas de errores e ilusiones que creíamos dogmas en un mundo de superabundancia de saberes, dispersos, parciales y fragmentados nos acercan visiones limitadas, que son en ocasiones fuentes de error. Uno de los 
grandes problemas de nuestro planeta, de la vida de los individuos como seres humanos en lo relativo al conocimiento. La Universidad enseña conocimientos, como muchos otros centros académicos, pero en pocos lugares se enseña qué es el conocimiento. Por ello que cada vez seamos más los universitarios que defendemos que ha de estudiarse el conocimiento del conocimiento. Por ello enseñar a vivir, enseñar a cuidar no es sólo enseñar a leer, escribir y contar o enseñar a prestar cuidados al cuerpo físico que nos acompaña. No es sólo enseñar conocimientos de geografía o historia, de las ciencias sociales o naturales, de la fisiología o anatomía. No es concentrarse en los saberes cuantitativos sin haber reflexionado y dar prioridad a las formaciones profesionales especializadas, de la que forma parte la enfermera.

Las múltiples historias que conforman cada método o estrategia de investigación revelan hasta qué punto cada práctica acarrea múltiples usos y significados. Descubrimos cómo y hasta qué punto nuestras certidumbres y creencias pueden engañarnos.

¿Significa que pretendo aportar la verdad? No. Nada más lejos de la verdad, pues sólo aporto ideas para luchar contra lo ilusorio, los errores y la parcialidad en la que nos movemos en nuestro entorno y sociedad con respecto a la en- fermería, su imagen y capacidad. Popper y otros investigadores demuestran sobradamente que las teorías científicas no aportan verdad absoluta y definitiva y que progresan superando sus errores. El camino de cuidar al otro es semejante, nació con el comienzo de la vida pues era necesario ocuparse del otro para que pudiera persistir para que la vida continúe y se desarrolle y, de este modo, luchar contra la muerte: la muerte del individuo, la muerte del grupo, la muerte de la especie (Collière, 1993: 5). No se trata de aportar recetas, sino reflexiones oportunas que sirvan para estimular, engrasar y despertar las mentes en lucha contra la parcialidad, los errores y las ilusiones en una época de desorientación e incertidumbre que en ocasiones raya el absurdo. En un periodo reciente en el que el covid19 y su avance requiere de más cuidadores profesionales que se ven constreñidos por las políticas institucionales y estatales que los obvian a ellos y a su voz. Cada vez más necesitamos una época de comunicación, una época de comprensión que será quien salve los cuidados y a quien los presta, al otro que es y se siente diferente, a las familias y a los extranjeros que somos todos.

Las dificultades académicas y disciplinarias que vive nuestra disciplina y profesión "la enfermería" de modo similar 
que la investigación cualitativa, manifiesta distintas sensibilidades, e ilustra diversas políticas inscritas en el campo de los discursos y de los desafíos. También la política sitúa la metodología dentro y fuera de la universidad, no siendo ajena a ello nuestra disciplina que a lo largo de su corta historia profesional es consciente de que generar conocimiento se antepone a su principal objetivo de cuidar al otro. En no pocas ocasiones, lo político y lo procedimental se cruzan y los científicos "duros" a menudo ponen en rango de "opinión" al considerarnos "blandos", pues de modo subliminal a quienes aportan el conocimiento sobre el cuidar los califican de conocimiento "no científico", más bien de conocimiento meramente exploratorio o subjetivo, femenino en sobradas ocasiones. Que forma parte de un ámbito en el que se define más a la disciplina como crítica, más que como teoría o ciencia, o se la interpreta políticamente como una versión disfrazada de un humanismo secular, si se acerca al otro desde una visión ética, o de marxismo cuando se entiende los comportamientos de las enfermeras como desafiantes cuando se enfrentan a los componentes de organización y dominación en el que desempañan su labor.
Cuidamos al otro y a sus familias y debemos reflexionar sobre la investigación necesaria para crear conocimiento de ello. Mientras, muchos investigadores alientan a emplear "metodologías rigurosas, sistemáticas y objetivas en aras al conocimiento válido y confiable"(Ryan y Hood, 2004: 80) instando a examinar modelos causales de explicación y variables independientes y dependientes bien definidas en el contexto de experimentos controlados y aleatorios, lo que les permite replicar y generalizar sus resultados. Esta investigación puede ser conveniente pero no exclusiva y no hace a otros modelos sospechosos de menos credibilidad tal como la investigación cualitativa.

Vivir y ayudar a que quien viva y ayude a los demás en las mejores condiciones de seguridad y dignidad, nos enfrenta sin cesar a nuestros semejantes, a una gama amplísima que se ha denominado otros para acortar así si son de aquí o de allá, jóvenes o adultos, hombres o mujeres, familiares o desconocidos, extranjeros... para conocerlos, cuidarlos y relacionarnos con ellos, y no hablo de relacionarnos con su cuerpo físico, necesitamos ir mucho más allá, comprender a ese alguien, a ese otro y ser comprendidos por él. 


\section{BIBLIOGRAFÍA}

Collière, M. F (1993). Promover la vida. McGraw-Hill / Interamericana de España. Madrid.

Denzin, N.K; Lincoln, Y. S (Coord.) (2012).

El campo de la investigación cualitativa. Vol. 1.

Gedisa Editorial. Barcelona
Morin, E. (2016). Enseñar a vivir. Manifiesto para cambiar la educación. Paidós. Barcelona.

Ryan, K.E., Hood, L.K. (2004). Guarding the castle and opening the gates. Qualitative Inquiry, 10: 79-85.

Dr. Alfonso Miguel García Hernández 